\title{
Lifeworks
}

\section{Virtual science}

\author{
Science in Art \\ Curator: Julie Bélisle \\ www.museevirtuel.ca/Exhibitions/Science/ \\ English/index.html \\ Sponsored by Heritage Canada and \\ Canada's Museum Community \\ Ongoing online exhibition
}

$\mathrm{D}$ oes this hurt? Would you call it a stabbing pain? A dull ache? Could you describe it a little more precisely?" Well, probably not. Pain is like that. Nobody can describe exactly what their personal suffering is like. You can't hand it over like a soft drink and say: "Here, try this." Which is probably why it has been a favourite subject for artists over the centuries. If art is an attempt to express the ineffable, the body is the perfect subject. Its torments have been a theme running through the arts from Shakespeare's Lear to Bach's St. Matthew Passion to Picasso's Guernica.

Today, probably as a result of much better health care, this corporeal obsession is expressed in a more positive way, in pop culture's fixation with fitness, attractiveness and sex. The less pleasant aspects of owning a body - disease, pain and aging are left to the purveyors of high culture. And these days high culture usually means "academic" art (once a pejorative term) since so much contemporary public art originates in university fine arts departments. This online exhibit, Science in Art, sponsored by Virtual Museum Canada, is no exception. Most of the artists are students or teachers from universities in Quebec and their works show the influence of that dark triumvirate of postmodernism: the philosophers Derrida, Foucault and Lacan.

Be prepared for some of the impenetrable artspeak that afflicts so much conceptual art. The descriptions that ac-

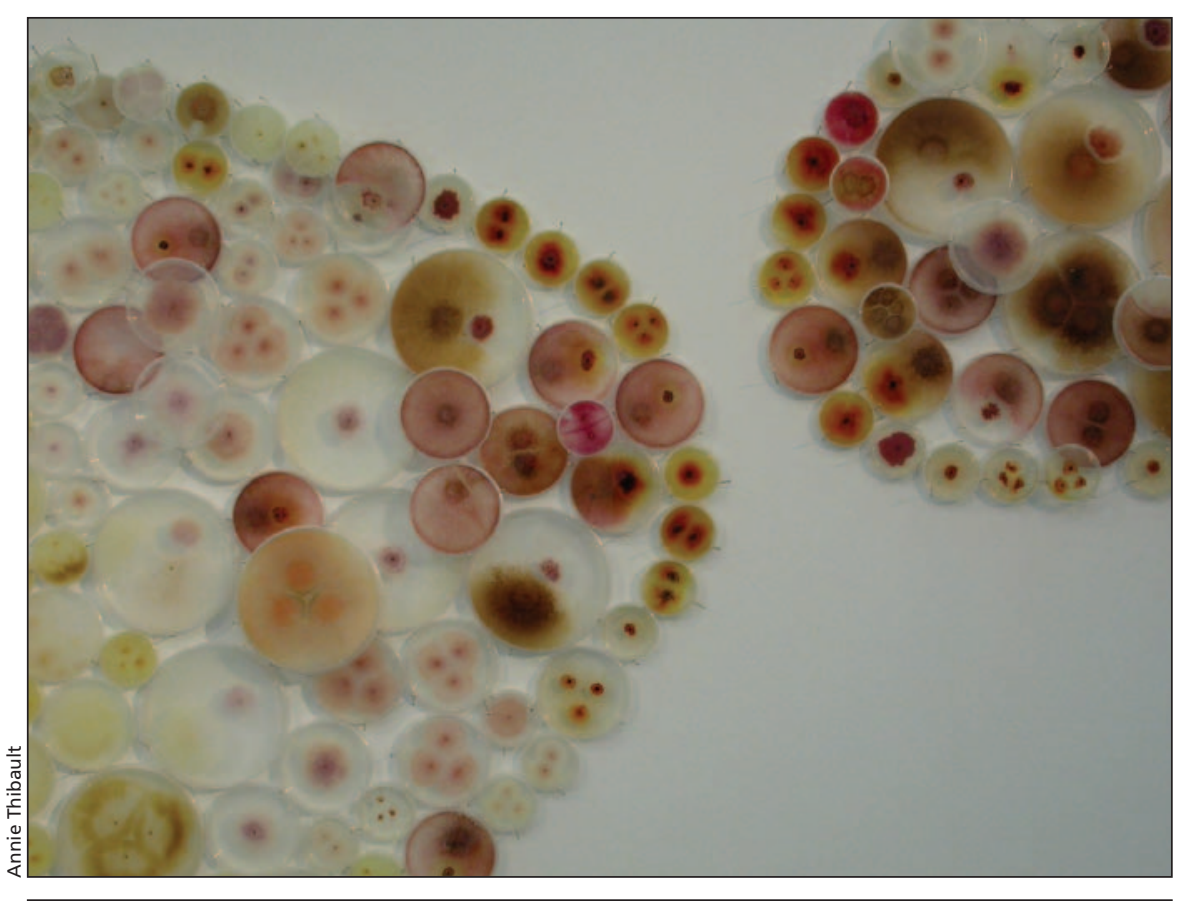

Annie Thibault, LABORATOIRE. Sous l'antre de la chambre stérile (detail) (2004). Petri dishes, agar-agar and fungal cultures inoculated in the laboratory.

company the pop-up images in this online exhibit may leave you scratching your head. But happily most of the artists have managed to transcend the theory and produced idiosyncratic and original work.

Annie Thibault is a Université du Québec à Montréal graduate who lives and works in Gatineau, Quebec. In an interesting marriage of art and science she arranges assemblages of petri dish and bacterial cultures on the gallery wall in swirling, circular patterns. Like so many things in nature, bacterial growths seen under a microscope can be surprisingly beautiful. Seen from this macro perspective with their varying shades of red and their almost Art Nouveau-style arrangement, the hundreds of dishes remind us that our innate esthetic impulse surely starts with an appreciation of the beauty of the natural world.

Chantal duPont, a professor at Université du Québec à Montréal, was diagnosed with cancer in 1999 and under- went radiotherapy. Self-representation is a frequent theme in her work and in this video piece she takes us through her ordeal. This is not a documentary in the usual sense. It's a deeply personal work of the imagination using visual metaphors to express her feelings about her disease and its treatment.

She presents the viewer with various scenarios. One deals with the hair loss from her chemotherapy. We see her wiping it from her head and blowing it out of her hands as if it were the fluff from a dandelion plant. Another scene shows the back of her bald head with a small toy being pulled by a string over the top of her skull. Looking at these scenarios brings to mind modern dance, where postures and gestures convey personal tragedy so much more powerfully than words.

Nicole Jolicœur's series of 19th century photographs explore the phenomenon of "dermography," which she defines as, "Sensitivity of the 


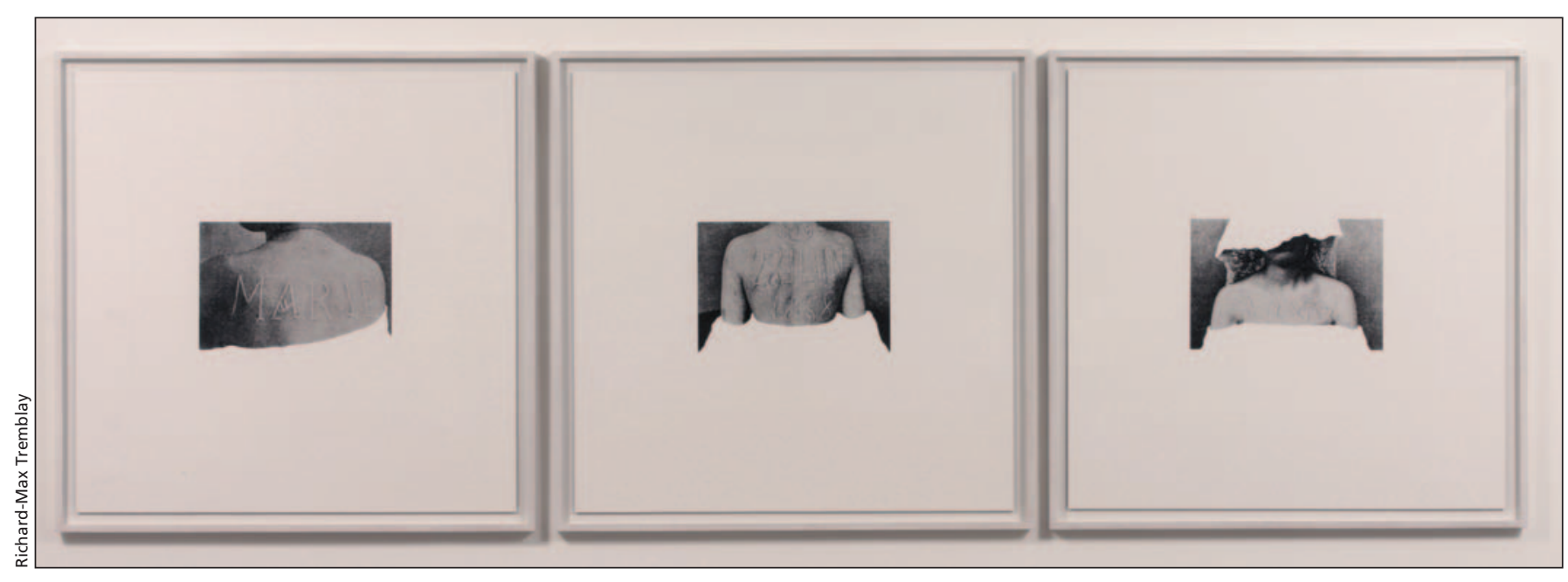

Nicole Jolicœur, Petites proses (1998). Photographic triptych, silver prints on paper. $120 \times 120 \mathrm{~cm}$ each. Collection of the Université du Québec à Montréal. Gift of the artist.

skin, which momentarily retains the imprints of writing or other marks drawn on it. In the 19th century, this phenomenon was considered to be a symptom of hysteria." The photos show 3 women whose welted skin spells out a word or a date in large print. The point here is not to investigate a discredited diagnosis but "point to the ambivalence and the element of belief associated with the scientific gaze, which thinks that it can adduce photographic proof to establish the iconography of inner turmoil."

In other words, the dazzling power of a new technology can lead people to the wrong conclusions. It's the uncertainty principle applied to medicine: the technology used in the diagnosis will inevitably affect the results.
Of course that interpretation may be completely off the mark. The solution may be just to look at the work and appreciate it on its own terms. Minus the explanations, some of it is very good indeed.

\section{Alan King BA}

Visual artist and art critic

Ottawa, Ont.

\section{Book review}

\section{Performance review}

\section{Better: A Surgeon's Notes on Performance Atul Gawande MD \\ Metropolitan Books/Henry Holt Company; 2007 \\ 273 pp \$14 paper ISBN 13 978-0312427658}

A s doctors, we spend a lot of time thinking: about patients, about their presenting complaints, about diagnoses. In the course of a whirlwind workday, however, finding $\approx$ the time to ponder one's performance objectively is often a luxury.

In his second book, Better, surgeon Atul Gawande demonstrates that he has made this activity a priority.

Gawande is an accomplished writer with an impressive pedigree, having

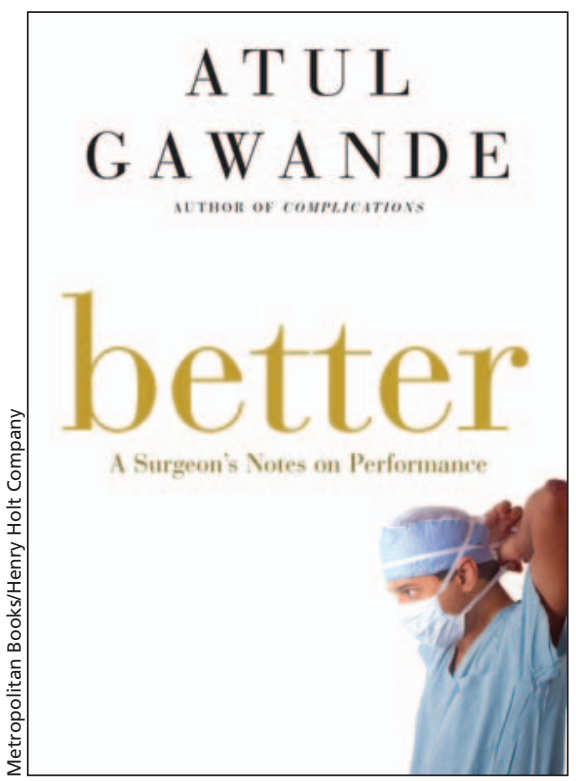

received both his doctor of medicine and master in public health from Harvard University, as well as a master of arts from Oxford University, he is now a staff writer at The New Yorker. In Better, Gawande methodically outlines his thoughts on how continuous innovation and improvement produces enhanced medical care. Drawing upon both research and anecdotes from the far reaches of the medical profession, he illustrates how small changes and determination can produce impressive, better, results.

He proposes 3 core attributes contributing to success in almost any risky field: diligence, ingenuity and doing right. Without "diligent attention to detail coupled with great ambition," public 